
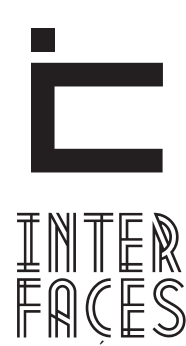

CIENTÍFICAS

HUMANAS E SOCIAIS

ISSN IMPRESSO 2316-3348

E-ISSN 2316-3801

DOI - 10.17564/2316-3801.2017v6n1p81-90

\title{
O FILME “MARIA, FLLHA DE SEU FLLHO” (2000) E SUAS DUAS MARIAS: A PRESENTIFICAÇÃO MARIANA NO ESPAÇO MIDIÍTICO E O IMAGINÁRIO SOCIAL FEMININO
}

\author{
THE MOVIE “MARIA: DAUGHTER OF YOUR SON" (2000) AND ITS TWO MARYS: MARIAN PRESENTIFICATION \\ IN MEDIA SPACE AND FEMALE SOCIAL IMAGINARY
LA PELÍCULA "MARÍA, HIJA DE SU HIJO" (2000) Y SUS DOS MARÍAS: PRESENTIFICACIÓN MARIANA EN EL ESPACIO MEDIÁTICO Y EL IMAGINARIO SOCIAL FEMENINO

\section{RESUMO}

0 artigo analisa a presença de Maria no filme "Maria, fitha de seu filho" (2000) dentro da concepção de "cultura de presença" de Hans Ulrich Gumbrecht, com o objetivo de perceber como a presença mariana, que dialoga com o imaginário social feminino (medieval) conservador, mas também com um novo imaginário ligado ao contexto histórico da produção do filme. Assim, esse filme apresenta-se como espaço de tensão entre dois imaginários femininos presentificados na personagem de Maria. Para isso, buscamos subsidio no instrumental teórico oferecido pelos estudos do imaginário social, através das contribuições de Cornelius Castoriadis e Bronislaw Baczko, bem como do aparato conceitual do "campo de experiência" e "horizonte de expectativa" de Reinhart
Koselleck para compreender como esses dois imaginários referentes a mulher, são presentificados através de Maria. Dessa forma, na tensão entre o imaginário social conservador feminino e o um novo imaginário sobre as mulheres, no filme "Maria, filha de seu filho" (2000) é possível encontrar informações que revelem a presença de um presente por meio de Maria, quando invoca pautas e projetos feministas, como liberdade de expressão e autonomia, o que rompe com seu imaginário tradicional.

\section{PALAVRAS-CHAVES}

Maria. Presença Mariana. Imaginário Feminino. 


\section{ABSTRACT}

The paper analyzes the presence of Mary in themovie "Maria: daughterofherson" (2000) withintheconceptof "cultural presence" Hans UlrichGumbrecht, in order to see how the Marian presence, that speaks to the female social imaginary (medieval) conservative, butal sowith a new imaginary linked to thehistorical contextof the productio nofthe film. Thus, thisfilmpresentsitself as voltage space betweentwo female imaginary made present in the character of Mary. For this, we seek to subsidize the theoretical tools off eredbythestudiesofthe social imaginary, throughthecontributionsofCorneliusCastoriadisandBronislawBaczkoandthe conceptual apparatusofthe "fieldexperience" and "horizonofexpectation"
ReinhartKosellecktounderstandhowthesetworeferringtoimaginarywoman, are madepresentthrough Mary. Thus, thetensionbetweenthefemaleconservative social imaginary and a new imagery of women in themovie "Maria: daughterofyourson" (2000) You can find information that reveals the presence of a giftthrough Mary, wheninvokesagendas andfeministprojects, such as freedomofexpressionandautonomy, which breaks with its traditionalimagery.

\section{KEY WORDS}

Mary. Marianpresence. Female imaginary.

\section{RESUMEN}

En este artículo se analiza la presencia de María en la película "María, hija de su hijo" (2000) dentro del concepto de "presencia cultural" de Hans Ulrich Gumbrecht, con el fin de ver cómo la presencia mariana, que dialoga con el imaginario social femenino (medieval) conservador, sino también con un nuevo imaginario relacionado con el contexto histórico de la producción de la película. Por lo tanto, esta película se presenta como el espacio de tensión entre dos imaginario femenino presente hecho en el carácter de María. Para ello, buscamos a subvencionar las herramientas teóricas ofrecidas por los estudios del imaginario social, a través de las contribuciones de Cornelius Castoriadis y Bronislaw Baczko y el aparato conceptual del "Espacio de experiencia" y "horizonte de expectativas" de
Reinhart Koselleck para entender cómo estos dos refiriéndose a la mujer imaginaria, se hacen presentes a través de María. Por lo tanto, en la tensión entre el imaginario social conservador femenino y un nuevo imaginario de la mujer en la película "María, hija de su hijo" (2000) Usted puede encontrar la información que revela la presencia de un presente por medio de María, cuando invoca agendas y proyectos feministas, como la libertad de expresión y la autonomía, que rompe con su imagen tradicional.

\section{PALABRAS CLAVE}

Maria. Presencia mariana. Imaginario femenino. 


\section{INTRODUÇ̃̃̃O}

O cinema, compreendido como arte e objeto de entretenimento e lazer, também é capaz de revelar informações sobre visões de mundo no imaginário social da época de sua produção. Assim, nos filmes que relatam a vida de Cristo, encontramos as principais imagens midiáticas sobre Maria, que tendem a revelar por meio de sua presença o imaginário feminino social oriundo de seu contexto, manifestando as mudanças e/ou permanências operadas na imagem da mulher na sociedade, uma vez que Maria é considerada um importante ícone e modelo de feminilidade para o mundo ocidental cristão.

Neste sentido, o filme italiano Maria, filha de seu filho, produzido no ano 2000 e que conta a tradicional história da vida de Cristo $^{1}$, se apresenta como fonte e espaço para a confluência de duas presenças marianas, relacionada a dois imaginários distintos. Na obra, a mãe de Jesus ora se apresenta com as características tradicionais, como por exemplo a virgindade, ora rompe com tais características, revelando novos atributos, como por exemplo um espírito de liderança ao ter voz ativa em uma sociedade patriarcal.

Desta forma, é possível identificar uma performatividade de duas presentificações marianas, sobretudo, dentro do instrumental teórico fornecido por Koselleck, entre um passado de Maria (campo de experiência) ligado ao seu imaginário tradicional, mas que conflui junto a um projeto de feminilidade (horizonte de expectativa) para as mulheres, no qual "[...] um determinado tempo presente, a dimensão temporal do passado entra em relação de reciprocidade com a dimensão temporal do futuro" (KOSELECK, 2006, p. 15).

Nossa proposta, portanto, é pensar como se configura a presença de Maria nesse filme de acordo com a concepção de cultura de presença de Gumbrecht (2010) e, com isso, tentar entender, as razões pelas quais esse filme, produzido em 2000, comporta dois imaginários tão distintos sobre Maria, resultando em

1. 0 filme, porém, utiliza evangelhos apócrifos sobretudo para narrar a juventude de Maria. duas formas de comportamentos (paradoxais). Esta obra, que apresentou um Cristo coadjuvante de sua própria história de vida, parece pertencer a um imaginário conservador e dogmático, ao mesmo tempo em que se apresenta como produto de seu tempo, ao abordar o feminino de maneiras diferenciadas, por meio de Maria.

Para compreender estas presenças, partiremos da figura de Maria como um arquétipo de feminilidade Cristã, que influenciou diretamente o modelo de conduta feminina na sociedade ocidental. Na sequência, para entender a presença de Maria nesse filme e como essa presença comporta dois imaginários contrastantes (um conservador tradicional e o outro menos ortodoxo), é preciso recorrer ao que Gumbrecht entende como "cultura de presença" e "cultura de sentido", além de compreender as oscilações e confluência do imaginário em torno de Maria, a partir dos estudos de imaginário social de Baczko (1985) e Castoriadis (1982). Por fim, seremos capazes de verificar as relações da obra cinematográfica com seu contexto, revelando assim uma abordagem contemporânea do feminino, que coexiste com um viés tradicionalista.

\section{AS IMAGENS DE MARIA E A CONSTRUÇÃO DO SEU IMAGINÁRIO TRADICIONAL}

A figura da virgem Maria ocupa papel de destaque no Cristianismo Católico e, consequentemente, na sociedade ocidental Cristã, sendo talvez o seu maior ícone feminino. Frequentemente apresentada com os atributos de submissão, maternidade, pureza e recato, Maria parece afirmar a ideia de um ambiente doméstico reservado, em especial, às suas seguidoras.

O século XII, segundo José Rivair Macedo (2002), é a época do impulso mariano, o tempo pleno de Maria, mãe de Jesus, que surge como redentora para as mulheres, libertando-as da maldição da queda. Esse é o momento em que celebram o regozijo do sexo feminino com a "nova Eva" símbolo da pureza, grandeza e santidade. 
De acordo com Jacques Dalarum (1990, p. 42), "A boa Maria deu a luz a Cristo, e em Cristo deu a luz aos Cristãos. É por isso que a mãe de Cristo é a mãe dos Cristãos e manifesta-se que Cristo e os Cristãos são irmãos”. Ele chama atenção que no século XIII, é possível perceber que os Mendicantes, sobretudo, os Franciscanos tomaram a dianteira em favor de difundir a virgem.

Ela agora é a nova Eva²; aquela que se permaneceu virgem se tornando o novo modelo a ser seguido. Maria é construída no referencial oposto a Eva, restaurando a condição das mulheres que vem para o seu lado e sua imagem como virgem pura e recatada é a tentativa de desfalcar o Diabo na Terra, sendo ela a única privada do estigma do pecado original.

Sendo assim, as imagens sobre a virgem Maria são relevantes na medida em que atribui às mulheres valores e comportamentos que definem seus papéis sociais, tornando-se o principal (re)produtor do imaginário social feminino do ocidente. Constrói-se a imagem da Mãe de Jesus como referencial de submissão, recato, pureza, obediência e que não decepcionasse mais a Deus e aos homens.

As imagens marianas em torno desses atributos se perpetuaram pelos séculos na cristandade Católica. Todavia, o filme Maria, filha de seu filho produzido em 2000, parece romper com esse imaginário quando apresenta também outro tipo de presença mariana, mais subversiva e heterodoxa, representado assim uma nova (re)significação, eco da produção de um novo imaginário social feminino no ocidente que incentiva a produção desse filme, como será abordado no item 4.

Antes de compreender a ruptura promovida pelo filme, porém, é necessário entender a obra cinematográfica como um espaço veiculador de presenças e imaginários sociais.

2. Eva foi criada a partir de uma costela de Adão, nascida do homem e, portanto, contrário à natureza. Conforme Séverine Fargette (2006, p.62), "é esse osso que correspondia exatamente ao espírito pérfido da mulher". Fato que se configura numa das justificativas da construção da inferioridade da mulher, posto que nasce depois do homem, não sendo criada diretamente por Deus (FARGETTE, 2006).

\section{A PRESENCCA MARIANA E SUAS INTERFACES COM O IMAGINÁRIO SOCIAL}

O conceito de produção de presença de Gumbrecht (2010) refere-se a produzir uma situação espacial de tangibilidade, em que se destaca os aspectos materiais da experiência, em detrimento das interpretações hermenêuticas. 0 autor pretende apreender as dimensões materiais da interação entre criatura e ambiente e as tensões que se desenvolvem no curso dessa experiência, o que vai determinar esse processo de produção de presença.

Gumbrecht (2010) destaca que houve uma supervalorização por parte da cultura ocidental (herança de um legado metafísico e cartesiano) do campo hermenêutico e seus modelos interpretativos dos fenômenos, reivindicando assim uma revisão dessas premissas. Como resultado dessa supervalorização, houve um crescente desejo de presença (não interpretativa) e o fascínio pelo passado no ocidente, que se manifesta, sobretudo, por meio da cultura de massas e das expressões artísticas. Sendo assim, o autor descreve duas formas de apreensão dos fenômenos culturais que não se pretendem excludentes, embora não sejam complementares: "cultura de presença" e "cultura de sentido".

[...] os fenômenos de presença não podem deixar de ser efêmeros, não podem deixar de ser aquilo que chamo de "efeitos de presença"; numa cultura que é predominantemente uma cultura de sentido, só podemos encontrar esses efeitos. Para nós, os fenômenos de presença surgem sempre como "efeitos de presença" porque estão necessariamente rodeados de, embrulhados em, e talvez até mediados por nuvens e almofadas de sentido. (GUMBRECHT, 2010, p. 135).

Em suma, Gumbrecht (2010) entende a presença como um efeito causado por uma materialidade, algo que seja tangível e que esteja diante de nós e, por isso, presente. Porém, essa presença pode se manifestar pela ausência da coisa em si, mas em um meio no qual o efeito de presença ainda aconteça, assim como o de sentido, diferentemente da hermenêutica (e aqui podemos mencionar o conceito de Represen- 
tações Sociais ${ }^{3}$ ), na qual a presença não se manifesta por meio do sentido e do significado, mas através de uma mídia que estimule por meio de uma intensidade grande ou fraca as suas sensações.

Esses conceitos, porém, não se excluem, principalmente ao pensar uma sociedade moderna, pois, segundo Gumbrecht (2010, p. 136) “É verdade, em princípio, que todas as nossas relações (humanas) com as coisas do mundo devem ser relações fundadas ao mesmo tempo na presença e no sentido [...]". No cinema, especificamente nas produções religiosas sobre Maria, ambos os efeitos acontecem: Maria tem um sentido e um significado, assim como manifesta uma presença, que poderia ser pensada em sua estética e na presentificação de seu passado enquanto símbolo.

Dessa forma, podemos trabalhar o filme como uma representação (produção de sentido) sem perder de vista a materialidade da presença em Maria, uma vez que ela presentifica tanto um passado por meio de seu imaginário tradicional quanto um presente, fruto do contexto histórico em que a produção do filme está inserido, revelando novos imaginários.

Importante salientar que o imaginário, conforme Castoriadis (1982), refere-se à capacidade dos homens de se representarem no mundo, sendo próprio do ser humano essa habilidade de criar e/ou recriar o real, o que forma uma espécie de magma ou energia criadora. 0 autor percebeu, assim, duas formas com as quais o imaginário social se apresenta: um imaginário que se conserva ou se mantém e um imaginário que se transforma, é produzido ou criado: permanências e rupturas.

Baczko (1985), por sua vez, destaca que são determinados momentos históricos que possibilitam a criação de um novo imaginário, que ele irá denominar tempo quente. Isso significa que durante algum tipo de conflito social (revolução, movimentos sociais etc.), é possível comover as estruturas e promover uma produção acelerada de significações para os acontecimentos e mutações no imaginário social vigente.

\footnotetext{
3 Podemos conceber conceito de representações sociais como as produções dos saberes sociais, que implicam na construção e transformação do conhecimento articulado com a ação e o pensamento conectado com a dinâmica social (CHARTIER, 1990; GINZBURG, 2001; JODELET, 2002, p. 17-44).
}

Dessa forma, ao estudar a presença mariana no filme Maria, filha de seu filho (2000), estamos em contato direto com o imaginário feminino social, tendo em vista que Maria e seu imaginário foi construído como modelo ocidental para as mulheres. Sendo assim, analisar a presença de Maria, em um determinado contexto geográfico, histórico e social repercute nas formas como os papéis de gênero são apresentados, traduzido em um imaginário social feminino. Tania Navarro Swain (1998) afirma que no imaginário marcado pelas relações entre os sexos (gêneros) e a formação de seus papéis sociais, há a construção da predominância masculina, sobretudo nas sociedades ocidentais, forjada como natural.

Veremos, agora, como essas confluências acontecem no interior da obra cinematográfica.

\section{FILME MARIA, FILHA DO SEU FILHO[2000] E SUAS DUAS MARIAS E A CONFLUÊNCIA DE DOIS PROJETOS DE FEMINILIDADES}

No decorrer do filme Maria, filha de seu filho (2000), que narra desde a juventude de Maria à crucificação e ressurreição de Cristo, é possível perceber a coexistência de duas formas como a presença de Maria é materializada e apresentada, indicando também dois imaginários distintos (conservador e novidade), o que não significa contradição ou incoerência, pois, como afirma Baczko (1985), os símbolos só se tornam eficientes quando estão ancorados numa comunidade de imaginação. Do contrário, tendem a desaparecer da vida coletiva ou ser reduzidos a funções decorativas.

Temos uma presença ligada ao imaginário mariano medieval, com uma visão de virgindade, maternidade, assunção (dogma reconhecido apenas em 1950, suscitando discussões no medievo), entre outros, ou seja, uma presentificação do passado (campo de experiência). Maria é presentificada no filme, o que a enquadra numa presença de um passado, sendo a Bíblia o principal instrumento/fonte de conexão com esse passado. 
A outra presença de Maria no filme (heterodoxa e inusitada) refere-se principalmente ao seu discurso, que presentifica o imaginário da época de sua produção. Dessa maneira, é possível perceber uma presença do presente com seus projetos (horizonte de expectativas), em que o discurso oferece materialidade a linguagem e oferece um efeito de presença ao espectador. Maria apresenta um discurso contemporâneo, que clama por igualdade de direitos e contesta os homens a todo o momento. Ela é fruto de seu contexto, apesar de ser um personagem com presença antiga. Comecemos, assim, com a presença de Maria ligada ao seu imaginário tradicional.

O filme Maria, figlia di suo figlio (2000), traduzido para o português como Maria, filha de seu filho (2000), é uma produção italiana, produzida por Sara Rossi e dirigida por Fabrizio Costa, que nos conta a história de Maria. Distribuído no Brasil pela Versátil Home Vídeo, foi produzido pela Titanus, empresa que se especializou em séries e filmes do gênero. Essa produção foi, originalmente, feita em duas partes de uma hora e vinte minutos cada.

Identificamos assim algumas passagens que corroboram com a presença de Maria que remete a um imaginário conservador, como a cena da anunciação pelo anjo e de que ela seria a progenitora do filho de Deus, mantendo-se virgem e imaculada; também apresenta a desconfiança de José e sua família, durante sua gravidez; a aparição do anjo para José, o persuadindo a acreditar em Maria, dentre muitos outros. Todavia, vamos destacar apenas duas dessas situações do filme para melhor aprofundarmos na identificação dessa presença e também para não incorrer no erro de sermos repetitivos ao mencionar essas muitas ocasiões.

O filme demonstra, logo no início, a crucificação de Cristo. Maria está junto de João e outras mulheres, acompanhando a cena. Nesse momento, temos uma referência ao Novo Testamento, quando Jesus coloca Maria "sob responsabilidade" do apóstolo João. Nessa passagem, o filme se refere ao evangelho de João, em que Jesus pede para sua Mãe olhar teu filho (João). Cristo confia sua Mãe aos cuidados de João, dialogan- do diretamente com o texto evangélico, que diz: "Jesus, então, vendo sua mãe e, perto dela, o discípulo a quem amava, disse à sua mãe: 'Mulher, eis teu filho'! Depois disse ao discípulo: 'Eis tua mãe!' E a partir daquela hora, o discípulo a recebeu em sua casa" (BÍBLIA, JOÃO, 19: 26-27).

Percebemos nessa cena, uma presença ortodoxa de Maria de duas formas bem próximas e ancoradas no Novo Testamento, o que dá uma dimensão de presentificação do passado: a primeira, diz respeito a Jesus, que transfere a tutela de Maria, que outrora foi passada para ele devido à morte de José, seu Pai, para João. Ela é tratada como uma herança, ou um bem patrimonial que, na morte de seu dono/tutor (Pai, Marido ou filho), passa para outro. Tal fato também remete a passagem do livro do Êxodo no Velho Testamento, quando a mulher é alçada como um bem do homem: "Não cobiçarás a casa de teu próximo. Não cobiçarás a mulher de teu próximo, nem seu escravo, nem sua escrava, nem seu boi, nem o seu jumento, nem coisa alguma que pertença a teu próximo"4 (BIBLIA, ÊXODO, 20: 17).

A segunda ancoragem incide sobre a fragilidade de Maria, porque ela, enquanto mulher já viúva e, agora com o filho morto, estaria mais vulnerável socialmente, precisando de alguém para cuidar dela. De qualquer forma, as duas situações presentificam uma imaginário sobre a mulher por meio de Maria, como incapaz de conduzir seu próprio destino, uma vez que está presa ao homem, seu protetor e possuidor de sua liberdade.

Reconhecemos também nesse episódio a presentificação de um passado por meio dos evangelhos canônicos, quando Cristo pede a João que receba sua mãe, conforme o texto evangélico de João e que pertence a um imaginário já estabelecido e/ou conservador. A presença de Maria, nesse momento no filme, condiz com seu imaginário tradicional. Aqui, podemos sentir o efeito de sua presença, quando apresenta estereótipos tão bem difundidos pela tradição, sobretudo a Católica, da mulher submissa e incapaz, que precisa da tutela de um responsável masculino.

4 Importante salientar que essa mesma passagem, de forma quase idêntica, também se encontra no livro do Deuteronômio capítulo 5, versículo 21. 
No roteiro do filme, é abordada a questão do censo decretado pelo Imperador Cesar Augusto, que exigiu a volta de todas as pessoas para suas cidades de origem para que pudessem ser registradas. José e Maria se encaminham para Galileia, em Belém. Todavia, Maria concebe Jesus durante a viagem, numa manjedoura, atraindo uma multidão.

Essa passagem condiz com o evangelho de Lucas: “[...] apareceu um edital de César Augusto [...] ordenando o recenseamento. Também José subiu da cidade de Nazaré, na Galiléia, para a cidade de Davi, chamada Belém, para a Judéia [...] para se inscrever com Maria, desposada com ele, que estava grávida" (BÍBLIA, LUCAS, 2: 1-4).

Assim, essa presentificação de Maria, ligada ao seu passado e ao campo de experiência está articulada com um imaginário conservador e que tem, como já foi dito, sua principal fonte ancorada na Bíblia. Nesse caso, a fonte é a conexão para presentificar um passado e/ou ethos em torno de Maria, por meio de sua atuação, bem como a forma que o filme se organiza e constrói a trama que gira em torno de Maria. A presentificação do passado de Maria invoca a forma como foi perpetuado seu imaginário, sempre legitimado pelos textos canônicos e que agora divide lugar com outra presença.

Em relação à presença que contrasta com esse imaginário mariano tradicional, enfatizaremos apenas duas dentre várias (que inclusive superam as presentificações conservadoras).

Após a escolha do noivo de Maria, ela é entregue à José que, inicialmente, parece se incomodar com o fato de ser mais jovem que ele. Ao sair do templo, ela o indaga: "Você conheceu muitas?"; ele, constrangido, diz que isso não é assunto para se falar. No entanto, Maria fala que já entendeu a situação e José questiona: “O que você entendeu?”, e ela responde: “Que não teve muitas mulheres". José fala para Maria montar no jegue para que partam e ela se recusa, tomando as rédeas do animal e seguindo à frente, guiando-o. José não gosta de sua atitude e afirma que ela não aguentaria dois dias de caminhada. Ela o contesta, e diz que se viajasse em cima do animal seria mais demorado. Seriam quatro dias.
Podemos observar que Maria questiona José a todo o momento. Ela não se cala e, por meio da curiosidade, o constrange quando pergunta sobre sua vida sexual e ainda deduz que ele teve poucas mulheres. Maria também desobedece a José e o desafia, não montando no animal e, por meio de argumentos, o persuade. Esses são elementos avessos ao imaginário tradicional mariano, sendo, na verdade, mais próximo dos estereótipos de Eva ou Lilith ${ }^{5}$, aquelas das quais as mulheres devem se afastar.

A rebeldia de Maria, somada a seu "atrevimento" ao perguntar sobre a vida sexual de José rompem com a tradição, e são características que permitem enquadrar a presença de Maria ao contexto de produção do filme, quando, por intermédio de suas ações e discurso, presentifica os ideias do feminismo (horizonte de expectativa), como liberdade de expressão (ao falar de sexo com o homem) e autonomia (não seguir as ordens do homem) no filme.

São situações que se alinham com o que Rago (2004) pontua sobre o discurso e postura feminista da geração pós-feminista, especialmente os que estão inseridos na classe média e/ou intelectualizada, no qual mantêm uma relação mais libertária com o sexo, o corpo, o outro, com a natureza e a própria vida.

Outro exemplo de rompimento com o imaginário tradicional pode ser visto quando Maria, ao voltar da casa de sua prima Elizabete (mãe de João Batista), para numa estalagem para passar a noite. Nesse momento, ela testemunha um grupo de homens fazendo chacota de um dos milagres de Jesus, chamando-o de farsante. Ela prontamente se pronuncia, dizendo que seu filho arrisca a vida dele para salvá-los, enquanto eles o ridicularizam. Contrariados, os homens questionam Maria, perguntando se ela não aprendeu que as mulheres não devem "se meter em assuntos de homens". Na ocasião, ela responde: "uma mulher deve defender a verdade, como todo mundo".

Existe aqui a explicitação dos papéis sociais de gênero, atribuindo ao feminino submissão e silêncio em rela-

5 Para maiores informações sobres os mitos de Lilith e Eva, consultar Fargette (2006). 
ção ao homem, detentor do poder de decisão e liderança. Maria presentifica, ao defender a (sua) verdade, outro tópico da atualidade presente nos debates feministas, que é a liberdade de expressão, tendo em vista que esses que não encontram referenciais nem no Novo Testamento ou nos textos apócrifos. São os direitos iguais que Maria presentifica, de maneira subversiva e heterodoxa, em oposição aos seus tradicionais atributos de submissão e ao imaginário mariano (e feminino) tradicional.

Dessa forma, podemos compreender o filme como um espaço de tensão temporal, no qual as duas presentificações marianas (uma presença mais presente que a outra) interagem, onde, segundo Koselleck (2006, p. 313-314) "não se pode conceber uma relação estática entre espaço de experiência e horizonte de expectativa. Eles constituem uma diferença temporal no hoje, na medida em que entrelaçam passado e futuro de maneira desigual".

A presentificação de um presente em Maria, por meio de seu discurso no filme, apresenta um ethos que diverge do seu imaginário tradicional, amplamente difundido como modelo de feminilidade ocidental. Essa presença está inserida no contexto de um novo imaginário, como um dos reflexos das transformações que a sociedade ocidental atravessou no decorrer da segunda metade do século XX no ocidente, ou seja, no seu horizonte de expectativa. Algo parece acontecer no universo das lutas sociais e políticas das mulheres, repercutindo, assim, nas atuações de Maria no filme.

Esse novo imaginário feminino que encontra eco na presença de Maria no filme nos remete ao "tempo quente" de Baczko (1985), que permite identificar a produção de novos imaginários, como dito anteriormente. Considerando como "tempo quente" a segunda metade do século XX em diante, compreendemos um imaginário social em relação ao feminino que possibilita as leituras feitas sobre o filme Maria, filha de seu filho (2000).

No decorrer desse período, identificamos alguns eventos que sacudiram o mundo em busca de uma nova ordem social e política, como o movimento de contracultura, que tem o beat generation (ou movimento beat) como uma das suas primeiras manifestações. De acordo com Silvia Maria Fávero Arend (2006, p. 108) nesse período da década de 1960, “em países da América do Norte e da Europa ocidental verificamos a eclosão de movimentos sociais - o Feminismo e a Contracultura - que tinham entre suas bandeiras de luta a crítica a determinadas práticas e valores da norma familiar burguesa".

Nesse cenário, também encontramos o movimento Hippie que é radicalmente oposto aos valores como trabalho, patriotismo e nacionalismo. Temos um movimento estudantil atuante, contestando principalmente os valores capitalistas, como aconteceu em Maio de 1968 na França e, no mesmo ano, também ocorreu na Tchecoslováquia, conhecido como a Primavera de Praga.

0 movimento feminista ${ }^{6}$ está inserido nesse contexto de contestações contra os valores vigentes, especialmente no pós-segunda guerra. Na verdade, constitui-se em uma importante força de luta contra um determinado ethos estruturado (patriarcal), e que se opõe às normas hegemônicas de atuação dos homens na sociedade. Em suma, busca, basicamente, a igualdade de direitos entre os homens e mulheres e a garantia da mesma participação feminina na sociedade, equivalente à dos homens.

A própria Itália, país de origem da produção do filme de Fabrízio Costa, compartilha dos avanços e reflexos das lutas femininas. Eric Hobasbawn (1995, p. 306) afirma que:

\begin{abstract}
0 primeiro e talvez mais impressionante exemplo dessa nova consciência de gênero foi a revolta das mulheres tradicionalmente fiéis nos países católicos romanos contra doutrinas impopulares da Igreja, como foi mostrado notadamente nos referendos italianos em favor do divórcio (1974); e leis de abortos mais liberais (1981) [...].
\end{abstract}

\begin{abstract}
6 Para Joana Maria Pedro (2005, p. 79-274): “0 feminismo, como movimento social visível, tem vivido algumas 'ondas'. 0 feminismo de 'primeira onda' teria se desenvolvido no final do século XIX e centrado na reivindicação dos direitos políticos - como o de votar e ser eleita -, nos direitos sociais e econômicos - como o de trabalho remunerado, estudo, propriedade, herança. O feminismo chamado de 'segunda onda' surgiu depois da Segunda Guerra Mundial, e deu prioridade às lutas pelo direito ao corpo, ao prazer, e contra o patriarcado - entendido como o poder dos homens na subordinação das mulheres. Naquele momento, uma das palavras de ordem era: 'o privado é político [...]" Para autoras como Teresa Aguilar García, depois da “'Segunda Onda' do feminismo, estaríamos vivendo a terceira onda: a da pós-modernidade. Momento em que se debatem o feminismo cultural e o ecofeminismo com o feminismo de quarta onda, que incluiria o feminismo queer de Judith Butler e o cyberfeminismo de Donna Haraway” (PEDRO, 2011, p. 270-283).
\end{abstract}


Mas outros fatores podem ter contribuído e motivado a produção desse novo imaginário mariano e feminino, que evidencia a presentificação do presente, materializado no discurso de Maria no filme Maria, filha de seu filho (2000). Dentro da Igreja Católica, no decorrer do século XX, (talvez em resposta ao feminismo) as discussões e decisões sobre Maria ganharam destaque, como a consagração do mundo ao Sagrado Imaculado Coração de Maria em 1942 (por meio das aparições de Fátima); a instituição do dogma mariano da Assunção em 1950; a publicação, em 1964, da bula papal Lumen Gentium que institui o culto a Nossa Senhora no credo Católico, entre outros.

\section{CONSIDERACÕES FINAIS}

A presença de Maria no filme Maria, filha de seu filho (2000) também dialoga com os movimentos sociais de contestação, quando Maria, por meio de suas atuações, presentifica não só o passado, por meio de seu imaginário tradicional, mas também rompe com ele, ao presentificar o presente por meio de ideários e pautas de movimentos de contestações como o feminismo. São essas características que presentificam um novo imaginário social para as mulheres, materializado no discurso e atuação de Maria e, introduzindo, portanto, uma descontinuidade na forma como ela está sendo elaborada na e pela sociedade.

Por fim, a presença de Maria performatizou duas presenças, sendo uma pertencente ao passado, ligado ao seu imaginário tradicional e um novo imaginário, fortemente influenciado pelo movimento feminista. As lutas femininas do século XX possibilitaram, assim, a presença de um novo imaginário sobre a Maria por meio do cinema, como produção de sentido. Desse modo, o cinema, enquanto obra de arte (sétima arte), presentificou o contexto social em que o filme analisado está inserido.

\section{REFERÊNCIAS}

AREND, Silvia Maria Fávero. Paradoxos do Direito de Família no Brasil (Uma Análise à Luz da História Social da Família). IN: SOUZA, Ivone, M.C. (Org.). Casamento: uma escuta além do judiciário. Florianópolis: VoxLegem, 2006.

BACZKO, Bronislaw. Imaginação social. Lisboa: Imprensa Nacional, 1985.

BÍBLIA DE JERUSALÉM. Evangelho de São João. São Paulo: Paulus, 2004.

BÍBLIA DE JERUSALÉM. Evangelho de São Lucas. São Paulo: Paulus, 2004.

BÍBLIA DE JERUSALÉM. Êxodo. São Paulo: Paulus, 2004.

\section{BLOCH, R. Howard. Misoginia medieval e a invenção}

do amor. Rio de Janeiro: 34, 1995.

\section{CASTORIADIS, Cornelius. A instituição imaginária}

da sociedade. Rio de Janeiro: Paz e Terra, 1982.

CHARTIER, Roger. A história cultural: entre práticas e representações. Rio de Janeiro: Bertrand, 1990.

CONSTITUIÇÃO Dogmática Lumen Gentium. Disponível em: <http://www.vatican.va/archive/ hist_councils/ii_vatican_council/documents/vatii_ const_19641121_lumen-gentium_po.html>. Acesso em: 13 nov. 2014.

COSTA, Fabrízio. Maria, filha do seu filho. EUA: Versátil Home Vídeo, 2000. (177 minutos)

DALARUM, Jacques. Olhares de Clérigos. In: DUBY, Georges; PERROT, Michelle (Org.). História das mulheres: a idade média. Porto: Afrontamento, 1990. 
EVANGELHO Apócrifo de Tiago. Disponível em: <http://www.autoresespiritasclassicos.com/ evangelhos\%20apocrifos/Apocrifos/Evangelhos\%20 Apocrifos.htm>. Acesso em: 11 dez. 2015.

FARGETTE, Séverine. Eva Lilith e Pandora o mal da sedução. Revista História viva: Duetto, n.12, São Paulo, 2006.

FARGETTE, Séverine. Eva Lilith e Pandora o mal da sedução. Revista História viva: Duetto, n.12, São Paulo, 2006.

GINZBURG, Carlo. Olhos de madeira: nove reflexões sobre a distância. São Paulo: Companhia das Letras, 2001.

GUMBRECHT, Hans Ulrich. Produção de presença: o que o sentido não consegue transmitir. Rio de Janeiro: Contraponto, 2010.

HOBSBAWM, Eric J. Era dos extremos: o breve século XX: 1914 -1991. São Paulo: Companhia das Letras, 1995.

JODELET, Denise. Representações sociais: um domínio em expansão. In JODELET, Denise (Org). As representações sociais. Rio de Janeiro: UERJ, 2002. p.17-44.
KOSELLECK, R. Futuro passado: contribuição à semântica dos tempos históricos. Rio de Janeiro: Contraponto, 2006.

MACEDO, José Rivair. A mulher na idade média. São Paulo: Contexto, 2002.

PEDRO, Joana Maria. Traduzindo o debate: o uso da categoria gênero na pesquisa histórica. HISTÓRIA, São Paulo, v.24, n.1, p.77-98, 2005. Disponível em: <http://www.scielo.br/pdf/his/v24n1/a04v24n1. pdf>. Acesso em: 16 mar. 2015.

RAGO, M. Feminismo e subjetividade em tempos pósmodernos. In: COSTA, C.L.;

\section{SCHIMIDT, S.P. (Org.). Poéticas e políticas}

feministas. Florianópolis: Mulheres, 2004. p.31-42.

\section{RANKE-HEINEMANN, Uta. Eunucos pelo reino de}

Deus: mulheres sexualidade e a Igreja Católica. Rio de Janeiro: Record/Rosa dos Tempos, 1996.

SWAIN, Tânia Navarro. De deusa a bruxa: uma história de silêncio. Brasília: UNB, 1998. 